ScIDice

\section{Prevalence and Analysis of Factors Associated with Maxillary First Premolar Class 1 Amalgam Restorations - A Retrospective Case Study}

Sindhu Priya Kuppusamy Sundara Murthy ${ }^{1}$, Delphine Priscilla Antony $\mathrm{S}^{2}$, Suresh V ${ }^{3}$

${ }^{1}$ Undergraduate Student, Department of Conservative Dentistry and Endodontics, Saveetha Dental College and Hospitals, Saveetha Institute of Medical and Technical Sciences(SIMATS), Saveetha University, Chennai 600 077, Tamil Nadu, India.

${ }^{2}$ Senior Lecturer, Department of Conservative Dentistry and Endodontics, Saveetha Dental College and Hospitals, Saveetha Institute of Medical and Technical Sciences(SIMATS), Saveetha University, Chennai 600 077, Tamil Nadu, India.

${ }^{3}$ Department of Prosthodontics, Saveetha Dental College ad Hospitals, Saveetha institute of medical and technical sciences, Saveetha University162, Poonamallee High Road, Chennai- 600077, Tamil Nadu, India.

\title{
Abstract
}

\begin{abstract}
Amalgam restoration has been the main procedure amid out over the last two centuries. There are many factors that affect it from stage of filtration, packing, finishing of material but studies on the effect of gender and age on treatment are scarce. The aim is to evaluate the age and gender and amalgam restorations in maxillary 1st Premolar with class 1 cavities. Data samples required for study were taken from hospital records. All the collected data were cross verified and compiled together in an excel sheet. Compiled data were statistically analysed in SPSS software. Within the limitations of this study, males and younger patients of ages 18-39 underwent higher number of amalgam restorations in maxillary 1 st premolar teeth with a p value of $0.081(<0.05)$. To conclude, males and younger patients chose to do more class 1 amalgam restorations in maxillary premolars.
\end{abstract}

Keywords: Amalgam; Dental Caries; Premolar Teeth; Restoration.

\section{Introduction}

Dental caries is an infectious-contagious disease that has a chronic multifactorial pattern. The presence of microorganisms on dental surfaces is essential for the development of caries disease, but only their presence is not enough [1] Factors such as hygiene, alimentary habits, bacterial colonization, time and saliva composition influence the metabolism of bacteria on teeth, leading to dental caries.

Dental caries is a disease that promotes destruction of dental hard tissues initially by the acid dissolution of the enamel mineralized matrix. If the lesion is not properly treated, it can progress through the dentin and reach the dental pulp [2] Most lesions are formed in the first mandibular molar, first maxillary molar, first maxillary premolar, first mandibular premolar, second mandibular premolar [3].

Dental amalgam is a mixture of a silver alloy with mercury and has been in use for over 200 years. This material provides strong, durable and good cost-effective direct posterior restoration. The use of amalgam for restoration of posterior teeth is due to its tolerance to a wide range of clinical placement conditions: biocompatibility, durability, availability, and desirable mechanical properties such as good compressive and flexural strength [4].

In a study done in Nigeria a total of 2,094 restorations found to meet in the criteria with males accounting for $691(33 \%)$ and females 1403 (67\%). Females also had more primary placements and replacements done for all the classes of restorations $[5,6]$.

There have been several studies on amalgam restorations in the past, however, very few of these studies had shown the effect of age and gender on treatment of amalgam for class 1 cavities [7].

A previous study was done on "Gender Distribution" of amalgam restorations and treatment patterns in regular attendees of a teaching hospital in Nigeria by Ajinde. The results of this study

*Corresponding Author:

Delphine Priscilla Antony S,

Senior Lecturer, Department of Conservative Dentistry and Endodontics, Saveetha Dental College ad Hospitals, Saveetha institute of medical and technical sciences, Saveetha

University 162, Poonamallee High Road, Chennai- 600077, Tamil Nadu, India.

E-mail: delphine.sdc@saveetha.com

Received: September 03, 2019

Accepted: September 29, 2019

Published: September 30, 2019

Citation: Sindhu Priya Kuppusamy Sundara Murthy, Delphine Priscilla Antony S, Suresh V. Prevalence and Analysis of Factors Associated with Maxillary First Premolar Class 1 Amalgam Restorations - A Retrospective Case Study. Int J Dentistry Oral Sci. 2019;S2:02:0014:66-69. doi: http://dx.doi.org/10.19070/2377-8075-SI02-020014

Copyright: Delphine Priscilla Antony S ${ }^{\circ}$ 2019. This is an open-access article distributed under the terms of the Creative Commons Attribution License, which permits unrestricted use, distribution and reproduction in any medium, provided the original author and source are credited. 
showed that more female patients attended and had higher number of restorations placed. There is a reduced female: male ratio for class 11 amalgam restorations [8].

Previously our team had conducted numerous clinical trials [8-11] and lab animal studies [12-19] and in-vitro students [20-23] over the past 5 years. Now we are focussing on epidemiological surveys. The aim of this study is to evaluate whether there is a correlation between age and gender in patients with amalgam restorations in maxillary 1 st premolar with class 1 cavities.

\section{Materials and Method}

All the data of patients who underwent amalgam restorations in maxillary 1 st premolars with class 1 cavities as study samples.

The study setting was a university setting. Exclusion criteria was case sheets with incomplete data, patients with amalgam restorations of other teeth (except 14,24), patients with other types of restorations except amalgam, those patients who did not come for follow up visits when called.

Data was collected from case sheets of patients who reported during the months of June 2019 to March 2020 from the hospital record management system where all the records of patients regarding their medical and dental history and treatment done are stored. All the data were covered by the following ethical approval number SDC/SIHEC/2020/DIASDATA/0619-0320. Cross verification was done to avoid bias by another examiner. To avoid missing any data, photographic evaluation was done.

All the relevant data were retrieved and tabulated in excel sheet.
Statistically analysed by IBM SPSS statistics version 21 was used. Dependent variables are age and gender. Independent variables tooth with amalgam filling.

\section{Results and Discussion}

The study consists of 33 patients, among which 14 were females, 19 were males. All the 33 underwent amalgam restorations in maxillary 1st premolars. $39.39 \%$ were from $18-29,39.39 \%$ from $30-39,12.12 \%$ from $40-49$, and $9.09 \%$ from $50-59$ age groups (Fig.1). 42.42\% were females and 57.58\% were males (Fig.2). $12.12 \%$ from $18-29,9.09 \%$ from $30-39,6.06 \%$ from $40-49$ and $9.09 \%$ from $50-59$ age groups underwent amalgam restorations in $14.27 .27 \%$ from $18-29,30.30 \%$ from $30-39,6.06 \%$ from $40-$ 49 with a p value of $0.081(<0.05)$ (Fig.3). $18.18 \%$ of males underwent amalgam restorations in 14 and the rest $39.39 \%$ in 24 . $18.18 \%$ of males underwent amalgam restorations in 14 and the rest $24.24 \%$ in 24 with a $\mathrm{p}$ value of $0.081(<0.05)$ (Fig.4).

In this study, the majority of the patients undergoing amalgam restorations were younger patients and males. The indication of placement or replacement of restorations or type of restoration depends on the ability and knowledge [24] of the dentist who is examining the patient. The subjectivity is an important factor, since a clinician can indicate the replacement of a restoration while others can suggest only the polishing of the same restoration [25].

Another study by Salmara et al., showed that dental caries was the main reason that led to the placement or the replacement of direct dental restorations, indicating that caries is still a significant dental problem in the population. It is possible to believe that the

Figure 1. Bar graph represents the percentage of patients with their age groups.

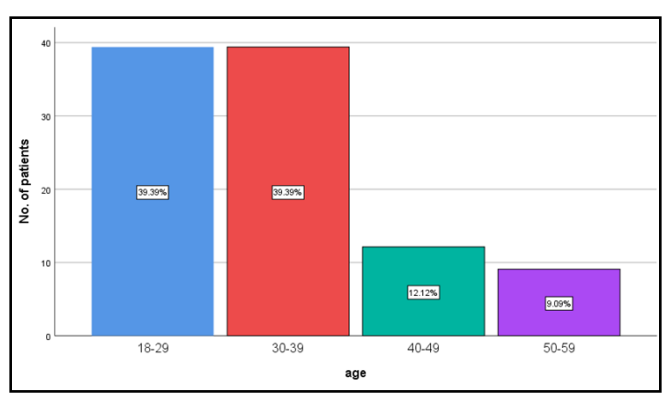

Bar graph represents the percentage of patients with their age groups. X-axis represents the age of the patients. Y-axis represents the percentage of patients. From the graph it is evident that 39.39\% were from $18-29$ (blue), 39.39\% from 30-39(red), 12.12\% from 40-49(green), and 9.09\% from 50-59(purple) age groups.

Figure 2. Bar graph represents the percentage of patients with their gender.

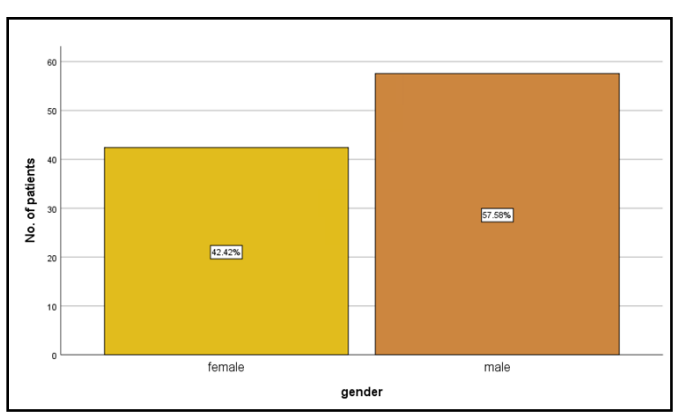

Bar graph represents the percentage of patients with their gender. X-axis represents the gender of the patients. Y-axis represents the percentage of patients. From the graph it is evident that $42.42 \%$ were females(yellow) and $57.58 \%$ were males(brown) 
Figure 3. Bar graph represents the association between Age and Tooth number.

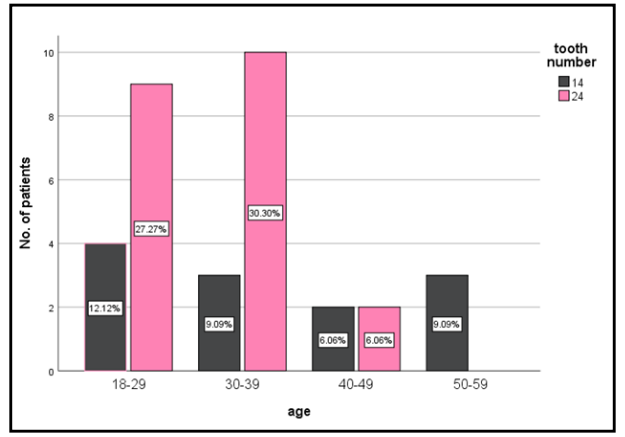

Bar graph represents the association between Age and Tooth number. X-axis represents the age of the patients. Y-axis represents the percentage of patients. Majority of the patients 30.30\% had amalgam restoration in 24(pink) in age group 30-39 and 14(grey) in age group 18-29. Chi-square test was done and the association was found to be statistically significant. Pearson's Chi-square value: 0.452 , DF:2, p value: $0.081(<0.05)$ hence statistically significant, proving that the younger the patients the higher the percentage of restorations.

Figure 4. Bar graph represents the association between Gender and Tooth number.

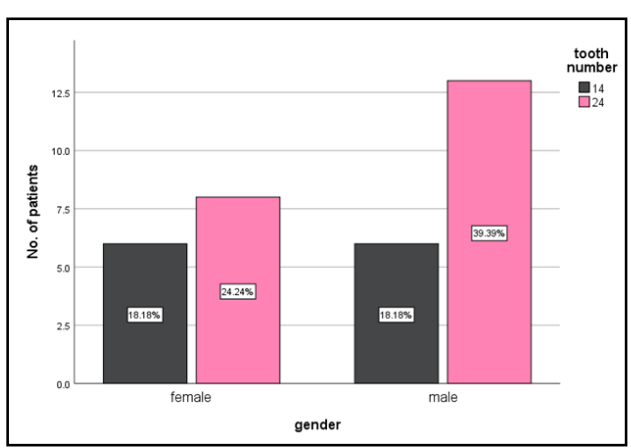

Bar graph represents the association between Gender and Tooth number. X-axis represents the gender of the patients. Y-axis represents the percentage of patients. More males, 39.39\% had amalgam restoration in 24(pink) and 18.18\% in 14(grey). Chi-square test was done and the association was found to be statistically significant. Pearson's Chi-square value: $0.116, \mathrm{DF}: 2$, $\mathrm{p}$ value: $0.081(<0.05)$ hence statistically significant, proving that more male patients underwent amalgam restorations.

occurrence of dental caries is not limited only to the individual issues, but also to social, economic, cultural and environmental factors [26].

A study by Ajinde was done for 13 years, showed more females underwent class 1 amalgam restorations and younger patients had more amalgam restorations in posterior teeth. A recent study by Denmark, the results showed an almost equal use of amalgam and composite was used more frequently in premolars [27].

Females had $67 \%$ of restorations placed while males had $33 \%$, indicating that females had more restorations by Tyas. The female: male ratio was 5:6. Males and females are exposed to detailed caries factors such as chewing gums and chocolates. Females tend to take time to attend to their oral health and attend clinics regularly [28].

The decision to replace an amalgam restoration for esthetics purposes was based on the desire of the patient to have a restoration similar to the colour of the tooth structure. In another study by Thomas J Hilton, younger patients considered aesthetics, so older patients received more amalgam restorations.

In this same aspect, factors related to the appearance of composite restorations, such as discoloration of the entire restorative material, margin discoloration and poor anatomic form were reasons that led to the replacement of composite restorations [29, 30].
Another reason to replace restorations can be the occurrence of secondary caries. This is closely related to the degradation of the margins of the restoration, leading to microleakage, that is the clinically detectable passage of bacteria, fluids, molecules or ions between the cavity wall and the restorative material. This may occur due to polymerization contraction stress of the composite, the use of incorrect adhesive and restorative techniques and if the dentist fills a cavity that has carious infected dentin. Secondary caries can also occur in amalgam restorations. Older patients and more posterior teeth receive an amalgam restoration have increased $[25,31]$.

The limitations of this study are the sample size, unicentric study and limited demographic data. This study could be further improved by increasing the sample size and check the various factors involved affecting the choice of restorations.

\section{Conclusion}

There are various available therapeutic possibilities for a restoration of tooth, damaged by tooth diseases or trauma of any kind. One of the oldest used restorations are Amalgam restorations, and they have proved to be successful to reconstruct posterior teeth, due their acceptance of tooth-decay extension and high occlusal forces. Within the limitations, the study concludes males and younger patients chose undergo more class 1 amalgam restorations in maxillary premolars. 


\section{Acknowledgment and Declarations}

First author, Sindhupriya performed the data collection by reviewing patient details, filtering required data, analysing and interpreting statistics and contributed to manuscript writing.

Second author, Dr. Delphine contributed to conception of study title, study design, analysed the collected data, statistics and interpretation and also critically revised the manuscript.

Third author, Dr. Suresh. V participated in the study and revised the manuscript. All the three authors have discussed the results and contributed to the final manuscript.

This research was supported by Saveetha Dental College and Hospital. We thank the department of Oral Medicine, Saveetha Dental College for providing insight and expertise that greatly assisted this research.

\section{References}

[1]. Featherstone JD, Doméjean S. The role of remineralizing and anticaries agents in caries management. Adv Dent Res. 2012 Sep;24(2):28-31.

[2]. Nascimento MM, Gordan VV, Qvist V, Litaker MS, Rindal DB, Williams $\mathrm{OD}$, et al. Reasons for placement of restorations on previously unrestored tooth surfaces by dentists in The Dental Practice-Based Research Network. J Am Dent Assoc. 2010 Apr 1;141(4):441-8.

[3]. Wood I, Jawad Z, Paisley C, Brunton P. Non-carious cervical tooth surface loss: a literature review. J Dent. 2008 Oct;36(10):759-66.Pubmed PMID: 18656296.

[4]. Shin WJ, Jeon YS, Lee KW, Lee HY, Han DH. Longevity and failure analysis of fixed restorations serviced in Korea. J Korean AcadProsthodont. 2005;43(2):158-75.

[5]. Mjor IA, Jokstad A, Qvist V. Longevity of posterior restorations. Int Dent J. 1990 Feb;40(1):11-7.

[6]. Widström E, Forss H. Dental practitioners' experiences on the usefulness of restorative materials in Finland 1992-1996. Br Dent J. 1998 Nov 28;185(10):540-2.Pubmed PMID: 9874887.

[7]. Tyas MJ. Placement and replacement of restorations by selected practitioners. Aust Dent J. 2005 Jun;50(2):81-9.

[8]. Barber T, Reisbick MH. Amalgam: past, present, and future. J Am Dent Assoc. 1973 Apr;86(4):863-9.Pubmed PMID: 4570007.

[9]. Ramamoorthi S, Nivedhitha MS, Divyanand MJ. Comparative evaluation of postoperative pain after using endodontic needle and EndoActivator during root canal irrigation: A randomised controlled trial. AustEndod J. 2015 Aug;41(2):78-87.Pubmed PMID: 25195661.

[10]. Ramanathan S, Solete P. Cone-beam Computed Tomography Evaluation of Root Canal Preparation using Various Rotary Instruments: An in vitro Study. J Contemp Dent Pract. 2015 Nov 1;16(11):869-72.

[11]. Siddique R, Sureshbabu NM, Somasundaram J, Jacob B, Selvam D. Qualitative and quantitative analysis of precipitate formation following interaction of chlorhexidine with sodium hypochlorite, neem, and tulsi. J Conserv Dent. 2019 Jan-Feb;22(1):40-47.Pubmed PMID: 30820081
[12]. Rajakeerthi R, Ms N. Natural Product as the Storage medium for an avulsed tooth-A Systematic Review. Cumhur. Dent. J. 2019;22(2):249-56.

[13]. Rajendran R, Kunjusankaran RN, Sandhya R, Anilkumar A, Santhosh R, Patil SR. Comparative Evaluation of Remineralizing Potential of a Paste Containing Bioactive Glass and a Topical Cream Containing Casein PhosphopeptideAmorphous Calcium Phosphate: An in Vitro Study. Pesqui. Bras. OdontopediatriaClín. Integr. 2019;19:1-10.

[14]. Hussainy SN, Nasim I, Thomas T, Ranjan M. Clinical performance of resinmodified glass ionomer cement, flowable composite, and polyacid-modified resin composite in noncarious cervical lesions: One-year follow-up. J Conserv Dent. 2018 Sep-Oct;21(5):510-515. PubmedPMID: 30294112.

[15]. Kumar D, Antony S. Calcified Canal and Negotiation-A Review. Res J Pharm Technol. 2018;11(8):3727-30.

[16]. Ravinthar K. Recent advancements in laminates and veneers in dentistry. Res J Pharm Technol. 2018;11(2):785-7.

[17]. Noor S. Chlorhexidine: Its properties and effects. Res J Pharm Technol. 2016;9(10):1755-60.

[18]. Teja KV, Ramesh S, Priya V. Regulation of matrix metalloproteinase-3 gene expression in inflammation: A molecular study. J Conserv Dent. 2018 Nov;21(6):592-6.

[19]. Janani K, Palanivelu A, Sandhya R. Diagnostic accuracy of dental pulse oximeter with customized sensor holder, thermal test and electric pulp test for the evaluation of pulp vitality: an in vivo study. Braz. Dent. Sci. 2020 Jan 31;23(1):8-p.

[20]. Jose J, Subbaiyan H. Different Treatment Modalities followed by Dental Practitioners for Ellis Class 2 Fracture-A Questionnaire-based Survey. Open Dent J. 2020 Feb 18;14(1).

[21]. Teja KV, Ramesh S. Shape optimal and clean more. Saudi Endod J. 2019 Sep $1 ; 9(3): 235$.

[22]. Manohar MP, Sharma S. A survey of the knowledge, attitude, and awareness about the principal choice of intracanal medicaments among the general dental practitioners and nonendodontic specialists. Indian J. Dent. Res. 2018 Nov 1;29(6):716-20.

[23]. Nandakumar M, Nasim I. Comparative evaluation of grape seed and cranberry extracts in preventing enamel erosion: An optical emission spectrometric analysis. J Conserv Dent. 2018 Sep-Oct;21(5):516-520.Pubmed PMID: 30294113.

[24]. Olaleye AO. Gender Distribution of Amalgam Restoration and Treatment Pattern in Regular Attendees of a Teaching Hospital in Nigeria. World. 2014 Apr;5(2):109-12.

[25]. Lubisich EB, Hilton TJ, Ferracane JL, Pashova HI, Burton B, PRECEDENT $\mathrm{N}$. Association between caries location and restorative material treatment provided. J Dent. 2011 Apr 1;39(4):302-8.

[26]. Mjör IA. Selection of restorative materials in general dental practice in Sweden. ActaOdontol Scand. 1997 Jan;55(1):53-7.Pubmed PMID: 9083577.

[27]. Mjör IA, Shen C, Eliasson ST, Richter S. Placement and replacement of restorations in general dental practice in Iceland. Oper Dent. $2002 \mathrm{Mar}$ Apr;27(2):117-23.Pubmed PMID: 11931133.

[28]. Friedl KH, Hiller KA, Schmalz G. Placement and replacement of amalgam restorations in Germany. Oper Dent. 1994 Nov-Dec;19(6):228-32.Pubmed PMID: 9028243.

[29]. Klausner LH, Green TG, Charbeneau GT. Placement and replacement of amalgam restorations: a challenge for the profession. Oper Dent. 1987 Summer;12(3):105-12.Pubmed PMID: 3476910.

[30]. Bhargava R, Parham DM, Lasater OE, Chari RS, Chen G, Fletcher BD. MR imaging differentiation of benign and malignant peripheral nerve sheath tumors: use of the target sign. Pediatr. Radiol. 1997 Feb 1;27(2):124-9.

[31]. Ellakwa AE, Shortall AC, Shehata MK, Marquis PM. Influence of bonding agent composition on flexural properties of an Ultra-High Molecular Weight Polyethylene Fiber-Reinforced Composite. Oper Dent. 2002 MarApr;27(2):184-91.Pubmed PMID: 11931138. 